\title{
Conceptions of sleep experience: a layman perspective
}

\author{
Maaike S. Goelema ${ }^{1,2^{*}}$, Renske de Bruijn ${ }^{3}$, Sebastiaan Overeem ${ }^{2,4}$, Els Møst ${ }^{1}$, Reinder Haakma ${ }^{1}$ \\ and Panos Markopoulos ${ }^{2}$
}

\begin{abstract}
Objective: To date, there is little information on how lay people understand and discuss sleep in the context of daily life. Efforts to conceptualize sleep quality have been largely driven by clinical considerations of sleep disorders. As such, they are not necessarily of how normal sleepers without clinical expertise conceptualize sleep quality. A phenomenological approach was taken to understand the essence of the sleep experience and the concepts held by lay people without sleep disorders. A sentence completion questionnaire was developed and administered to a quota sample of 64 respondents who were selected aiming for sufficient representation of different gender, ages, and education levels.

Results: Significant sentences and meaningful units were derived inductively, resulting in a classification of nine categories. The major facets of sleep experience of lay people were 'daytime functioning', 'interruptions during the night' and 'before bed state.' This implies that the experienced sleep quality is not only depending on the progress of the night. These results can guide future research to provide suitable psychometric measures for normal sleepers, as well as the design of sleep data visualization applications in the context of health self-monitoring.
\end{abstract}

Keywords: Perceived sleep quality, Sleep behavior, Health monitoring, Phenomenology

\section{Introduction}

In recent years, there is a growing trend towards selfmonitoring of sleep quality using commodity electronics, typically based on self-report or activity level measurements [1]. While such technologies are not yet meant as a tool to support clinical practice, the need arises to represent sleep quality in terms that are understood by people and are meaningful with respect to how they experience sleep [2,3]. In addition, since sleep is related to a variety of health outcomes [4-6], understanding how lay people describe and understand sleep is important as addressing certain sleep issues may improve other health outcomes as well.

Defining and operationalizing sleep quality is challenging and a broadly accepted definition is still lacking. Traditionally clinical research has sought to define and

\footnotetext{
*Correspondence: mgoelema@gmail.com

1 Philips Group Innovation Research, High Tech Campus 34, 5600 MB Eindhoven, The Netherlands

Full list of author information is available at the end of the article
}

operationalize sleep qualities by developing purpose specific questionnaires that are based on a clinical understanding of sleep disorders. Such questionnaires are not necessarily reflective of how lay people without sleep disorders conceptualize sleep and think about their own sleep experience. Krystal and Edinger [7] proposed to measure sleep quality based on the Likert-style rating of sleep quality of the previous night without attempting to further detail or conceptualize what sleep quality should be assumed to refer to.

Research regarding the sleep experience of normal sleepers is limited [8-10]. Harvey et al. [8] conducted structured interviews which helped them identify the following factors as the most important for judging subjective sleep quality the morning after: whether you got enough sleep, how tired you feel throughout the day, how rested you feel when waking up, feeling restored on waking and feeling alert throughout the day. Buysse et al. [11] observed that subjective sleep depth falls along the same dimension as overall sleep satisfaction. A broader consideration may be needed as to what the general sleep

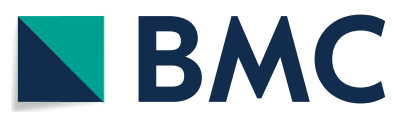

(c) The Author(s) 2018. This article is distributed under the terms of the Creative Commons Attribution 4.0 International License (http://creativecommons.org/licenses/by/4.0/), which permits unrestricted use, distribution, and reproduction in any medium, provided you give appropriate credit to the original author(s) and the source, provide a link to the Creative Commons license, and indicate if changes were made. The Creative Commons Public Domain Dedication waiver (http://creativecommons.org/ publicdomain/zero/1.0/) applies to the data made available in this article, unless otherwise stated. 
experience is for normal sleepers, starting from what someone needs to go to sleep, to how a person awakes the best, to improve our understanding of what is a good sleep experience and subsequently sleep quality.

Since there is little information on how lay people understand and discuss sleep in the context of daily life, the aim of the current paper is to provide insight into the sleep experience of lay people. A phenomenological research approach is taken that aims to capture the essence of an experience common to a group of people, bracketing out prior conceptions of this experience on behalf of the researcher.

\section{Main text \\ Methods \\ Participants}

Ethical approval was received from the Institutional Ethical Review Board of Eindhoven University of Technology. Participants were recruited through a database maintained at the University and approached by email. Participants could interact with the researchers through a website. The whole study was conducted online. A quota sampling approach was applied in order to ensure that the following subgroups were sufficiently represented in the final sample:

- Age: young ( $\leq 49$ years)/old ( $\geq 50$ years).

- Sex: female/male.

- Education: high ( $\geq$ bachelor)/low (<bachelor).

- Pittsburgh Sleep Quality Index (PSQI) [12]: good $(\leq 5) /$ poor $(>5)$.

In each of the combination of these groups, we had at least 4 participants, which made the total number of participants for the analysis of this study 64 (2 age* 2 sex $^{*} 2$ education * 2 PSQI * $4=64$ participants). Persons with a formally diagnosed sleep disorder were excluded from participation.

However, we did not actively screen the sample for signs of-undiagnosed-sleep disorder, as the wider community population also consists of people who experience sleep problems and people who do not.

\section{Measures}

Sentence stem completion questionnaires [13] were used to survey participants' conceptions of sleep experience. Stem completion is a projective data collection technique which was originally developed as part of an intelligence test. Initially, a pool of 62 Dutch sentence stems was derived based on examination of existing subjective sleep quality inventories [12, 14-17]. A pilot trial of the 62 -item stem completion questionnaire was carried out with 10 individuals, recruited through convenience sampling amongst colleagues in the research groups of the authors. The responses were analyzed for word frequency and comparisons were made between responses depending on whether a participant indicated to be sleeping well, poorly, or neutral. Removing stems that did not seem to provide new information left 30 sentence stems over, resulting in the Sleep Sentence Completion Questionnaire (SSCQ). Translations of the items of the questionnaire can be found in Additional file 1.

\section{Procedure}

After informed consent we checked that participants were native Dutch speakers, to ensure adequate comprehension of the stems and the ability to express themselves adequately. Filling in the survey took $15^{\prime} \mathrm{min}$. Demographic information, educational level, the Dutch version of the Pittsburgh Sleep Quality Index (PSQI) [12] and SSCQ were assessed. The PSQI is a validated questionnaire, for the assessment of sleep quality, with a Dutch translation available (Sillis and Cluydts, unpublished data of 'personal communication'). Objective sleep measurements were not included as it was not relevant for our research question whether people had a good or poor night's of sleep. In addition, most sleep questionnaires are not necessarily reflective of how lay people perceive their sleep. Finally, previous studies observed low to medium associations between objective sleep measurements and subjective sleep quality [18-21].

\section{Data analysis}

A phenomenological data analysis approach was adopted. Phenomenology is a qualitative research approach which aims at describing the common meaning of lived experiences for several individuals, reducing the experiences reported by individuals to a central meaning, or the 'essence' of the experience [22].

Completed questionnaires were read one by one in their entirety and analyzed to identify the most meaningful statements per participant (in total 64 participants). No fixed number was set, but we aimed for selecting approximately 1-5 meaningful statements per participant in order to reduce the data set. Selected meaningful statements for the full set of participants were clustered into themes, now representing the whole participant population. This resulted in a set of 206 significant statements, which were clustered into eight themes, based on the frequency of the statements and their similarities. Since the statements were already short in itself no software was used to analyze the statements.

To ensure the validity of the clustering, two coders performed independently a direct content analysis [23] where they classified all the statements $(64 \times 30=1920)$ along the eight themes. After $5 \%$ of the data, a comparison table was created to identify divergent classifications 
and interpretations. Based on this discussion, another category was added, namely: alarm clock. The remaining 1800 statements were classified by the two coders achieving a consistency of 0.81 Cohen's kappa.

\section{Results}

The characteristics of the study sample are displayed in Table 1 . The average total sleep time of the study sample was $\pm 8 \mathrm{~h}$.

The nine themes that resulted from the data analysis can be found in Table 2. The largest category in our analysis was 'next day state', characterized by the following statements: whether people felt tired the next day, whether they felt restored the next day, how refreshed or rested they felt when waking up or whether they felt energetic during the day.

\section{Table 1 Participants characteristics}

\begin{tabular}{ll}
\hline Characteristics & \\
\hline Age, mean (SD) & $47(18.2)$ \\
Age range & $18-79$ \\
Gender & $32(50 \%$ female) \\
PSQI, mean (SD) & $5.9(3.7)$ \\
PSQI range & $1-16$ \\
Time to bed, mean (SD) & $23: 38: 59(1: 13: 42)$ \\
Wake up time, mean (SD) & $7: 31: 41(1: 11: 35)$ \\
\hline
\end{tabular}

$S D$ standard deviation
Statements about sleeping through the night and waking up during the night were included in the second category: interruptions. The interruptions category can be divided into two parts, one part where internal reasons were given for the interruptions during the night (waking up in general and toilet visits) and a second part where external reasons were given for not sleeping through the night (noise and waking up by others).

The third largest category 'before bed state' contained concepts about the mental status before going to bed and the body state in which subjects entered the bed. For instance, 'I sleep well when I am not worried or stressed before bedtime.

190 statements of the 206 statements were accommodated under the 8 categories. Statements that were not included in the 8 categories but were allocated in the category 'other' concerned: dreams/nightmares (4), regular bedtimes (2), bad food (3) and some few single statements (7). However, after the validity of the coding, the category 'other' came out quite large as statements about sleeping posture, sleep rhythm and sleeping on time could not be designated under the other categories but were mentioned quite often.

\section{Discussion}

In our study, daytime functioning was one of the most important factors for describing the sleep experience. In other words, the energy level during the day, how tired

Table 2 The outcome of the categorization of the 206 statements about sleep experiences

\begin{tabular}{|c|c|c|c|}
\hline Themes & Description & Example & \#statements \\
\hline Next day state & $\begin{array}{l}\text { Includes statements about the state of well-being } \\
\text { directly after waking up and daytime function- } \\
\text { ing }\end{array}$ & $\begin{array}{l}\text { After a good night's sleep: I feel fit and energized, and } \\
\text { looking forward to the day }\end{array}$ & 51 \\
\hline Interruptions during the night & $\begin{array}{l}\text { Contains statements about waking up through } \\
\text { the night either induced by internal causes (toi- } \\
\text { let visits) or external causes (noise). Also includes } \\
\text { the positive stated statements, such as sleeping } \\
\text { through the night }\end{array}$ & $\begin{array}{l}\text { A good night's sleep is: minimizing the number of } \\
\text { awakenings during the night }\end{array}$ & 41 \\
\hline Before bed state & $\begin{array}{l}\text { Involves statements about mental and physical } \\
\text { well-being before going to bed }\end{array}$ & What most affected my sleep was: stress & 39 \\
\hline Sleep characteristics & $\begin{array}{l}\text { Contains the other sleep parameters such as sleep } \\
\text { onset latency, deep sleep and sleep duration }\end{array}$ & I feel best when: I have slept $8 \mathrm{~h}$ & 18 \\
\hline Bedroom environment & $\begin{array}{l}\text { This theme is about all the objects in the bedroom } \\
\text { (for instance, bed, mattress, pillow etc.) and the } \\
\text { light and temperature in the bedroom }\end{array}$ & $\begin{array}{l}\text { What my sleep interrupts is: too much light through } \\
\text { the window }\end{array}$ & 13 \\
\hline Thoughts about sleep & $\begin{array}{l}\text { Statements about how they perceive sleep and } \\
\text { the function of sleep }\end{array}$ & lexperience my sleep: as important & 12 \\
\hline Routine & $\begin{array}{l}\text { Contains statements about bedtime routines such } \\
\text { as listening to music or drinking habits before } \\
\text { bedtime }\end{array}$ & Before bedtime: I would like to read a book & 11 \\
\hline Alarm clock & $\begin{array}{l}\text { Statements that include either waking up with or } \\
\text { without an alarm clock }\end{array}$ & $\begin{array}{l}\text { I cannot fall asleep without: first setting the alarm } \\
\text { clock }\end{array}$ & 5 \\
\hline Other & $\begin{array}{l}\text { This theme contains all the other statements } \\
\text { which do not belong to the other themes }\end{array}$ & My sleep is poor when: I dream a lot & 16 \\
\hline
\end{tabular}


or refreshed they felt when waking up, were frequently described when answering the SSCQ. This suggests that daytime functioning is more important for people to judge their sleep experience than the actual night itself. Still, wake time during the night cannot be ignored, as this also formed a large category in our analysis. In the study of Ramlee et al. [9] wake time during the night was not a major factor when judging sleep quality. Compared to the study of Harvey et al. [8], our participants indicated that their state of mind before bedtime is an import factor for the sleep experience. State of mind, such as stress, has been correlated with subjective sleep quality [24-26]. The categories are linked though, as stress before going to bed can cause a longer sleep onset latency, more awakenings during the night and therefore a shorter sleep duration $[27,28]$. As a consequence, one may feel tired during the day. Overall our study gave insight in the whole sleep experience of lay people whereas (in general) abovementioned studies only considered judgements of participants on a good and poor night's of sleep.

When comparing the PSQI with our categorization we saw one remarkable thing. The major category daytime functioning did not match with the questions of the PSQI, in particular, because of the different wording of the questions of the PSQI. The PSQI questions relate more to the extremes of daytime functioning, for instance: 'During the past month, how often have you had trouble staying awake while driving, eating meals, or engaging in social activity?? Probably, most people do experience some degree of dysfunction during the day because of tiredness or not feeling refreshed, however, they do not experience problems with staying awake.

As the perception of sleep is not always related to the actual sleep, this may explain the low correlations between objective and subjective sleep measurements often found [19, 29-31]. For sleep monitoring devices or sleep coaching apps this is important to consider, as sometimes the data contrasts with what people feel. Additionally, this may implicate that the data shown by a device should be interpreted with caution.

This study was conducted with a balanced study sample. A phenomenological approach was used to analyze the qualitative data to capture the participant perspective and what they report as their sleep experience. The study results are likely generalizable to the broader community sample, which also contains a proportion of people with sleep problems, or undiagnosed sleep disorders. A suggestion for future research would be to develop a new validated sleep questionnaire that covers the whole range of the sleep experience to gain a better understanding of the subjective sleep quality.

\section{Conclusion}

Our results imply that the experienced sleep quality is not only depending on the progress of the night. The sleep quality definition should, from a subjective point of view, be elaborated with other factors, such as stress/ well-being levels, feeling of being rested and functioning during the day. These results can guide future research to provide suitable psychometric measures for normal sleepers, since some parts of the sleep experience of lay people are not addressed in the sleep quality questionnaires at the moment. In addition, with the emerging trend of consumer activity trackers above results could provide guidance in the design of the feedback towards the users, e.g. including educational information about sleep relaxation exercises or a tab where users can indicate their level of stress before going to bed. This will contribute to an insight in the overall sleep experience of the user.

\section{Limitations}

Several limitations of our study should be acknowledged. While the use of a sentence completion questionnaire allowed an understanding of the intuitive sleep concepts of lay people, the questions of the SSCQ were guided questions as they asked about specific facets of sleep. More open questions may have yielded the risk that not every aspect of sleep was covered, as the pitfall emerges of repeating oneself. With the SSCQ we were able to capture the whole picture of participants' perspectives about sleep. We tried to reduce the experimenter bias as much as possible through calculating the interrater reliability. Although several age groups were included in this study we cannot rule out that we have corrected for all the factors that impact sleep, such as unemployment, medication and chronic pain. Finally, since our study sample consisted of Dutch participant the results may not culturally generalizable to other countries.

\section{Additional file}

Additional file 1. Sleep Sentence Completion Questionnaire. English translation of the Sleep Sentence Completion Questionnaire.

\section{Abbreviations \\ SSCQ: Sleep Sentence Completion Questionnaire; PSQI: Pittsburgh Sleep Quality Index.}

\section{Authors' contributions}

$\mathrm{RB}, \mathrm{EM}, \mathrm{RH}$ and $\mathrm{PM}$ participated in the design of the study; RB collection of data; MG, SO, EM, RH and PM analyzed and interpreted data; MG drafted the manuscript. All authors read and approved final manuscript. 


\begin{abstract}
Author details
1 Philips Group Innovation Research, High Tech Campus 34, 5600 MB Eindhoven, The Netherlands. ${ }^{2}$ Department of Industrial Design, Eindhoven University of Technology, Den Rondom 70, 5612 AZ Eindhoven, The Netherlands. ${ }^{3}$ Department of Human Technology Interaction, Eindhoven University of Technology, Eindhoven, The Netherlands. ${ }^{4}$ Sleep Medicine Center, Kempenhaeghe, Heeze, The Netherlands.
\end{abstract}

\section{Acknowledgements}

Not applicable.

\section{Competing interests}

$\mathrm{RH}$ and EM are employees of Royal Philips.

\section{Availability of data and materials}

The datasets used and/or analyzed during the current study are available from the corresponding author upon reasonable request.

\section{Consent for publication}

Not applicable.

\section{Ethics approval and consent to participate}

Ethical approval was received from the Institutional Ethical Review Board of Eindhoven University of Technology. Participants were recruited through the 'IPO database of study participants' maintained at the University. This database consists of students as well as people who indicated to be willing to participate in future research studies. Informed consent was obtained online by all participants. Participants were paid with a voucher of 5 Euro.

\section{Funding}

This work was supported by POINT ONE, a government agency providing general funding for the project. Royal Philips, a commercial sponsor providing general funding for the (Ph.D.) project.

\section{Publisher's Note}

Springer Nature remains neutral with regard to jurisdictional claims in published maps and institutional affiliations.

Received: 19 October 2017 Accepted: 7 July 2018

Published online: 18 July 2018

\section{References}

1. Ko PT, Kientz JA, Choe EK, Kay M, Landis CA, Watson NF. Consumer sleep technologies: a review of the landscape. J Clin Sleep Med. 2015;11:1455-61.

2. Evenson KR, Goto MM, Furberg RD. Systematic review of the validity and reliability of consumer-wearable activity trackers. Int J Behav Nutr Phys Act. 2015;12:159.

3. Piwek L, Ellis DA, Andrews S, Joinson A. The rise of consumer health wearables: promises and barriers. PLOS Med. 2016;13:e1001953.

4. Beebe DW. Cognitive, behavioral, and functional consequences of inadequate sleep in children and adolescents. Pediatr Clin North Am. 2011;58:649-65.

5. Chee MW, Chuah LY. Functional neuroimaging insights into how sleep and sleep deprivation affect memory and cognition. Curr Opin Neurol. 2008;24:417-23

6. Kim D-J, Lee H-P, Kim MS, Park Y-J, Go H-J, Kim K-S, et al. The effect of total sleep deprivation on cognitive functions in normal adult male subjects. Int J Neurosci. 2001;109:127-37.

7. Krystal AD, Edinger JD. Measuring sleep quality. Sleep Med. 2008;9(Supplement 1):S10-7.
8. Harvey AG, Stinson K, Whitaker KL, Moskovitz D, Virk H. The subjective meaning of sleep quality: a comparison of individuals with and without Insomnia. Sleep. 2008;31:383-93.

9. Ramlee F, Sanborn AN, Tang NKY. What sways people's judgment of sleep quality? a quantitative choice-making study with good and poor sleepers. Sleep. 2017. https://doi.org/10.1093/sleep/zsx091.

10. Means MK, Edinger JD, Glenn DM, Fins Al. Accuracy of sleep perceptions among insomnia sufferers and normal sleepers. Sleep Med. 2003:4:285-96

11. Buysse DJ, Yu L, Moul DE, Germain A, Stover A, Dodds NE, et al. Development and validation of patient-reported outcome measures for sleep disturbance and sleep-related impairments. Sleep. 2010;33:781-92.

12. Buysse DJ, Reynolds CF III, Monk TH, Berman SR, Kupfer DJ. The Pittsburgh sleep quality index: a new instrument for psychiatric practice and research. Psychiatry Res. 1989;28:193-213.

13. Dittmann-Kohli FE, Westerhof GJ. The sele sentence completion questionnaire: a new instrument for the assessment of personal meaning in research on aging. Anu Psicol UB J Psychol. 1997;73:7-18.

14. Morin CM, Barlow DH. Insomnia: psychological assessment and management. New York: Guilford Press; 1993.

15. Van Diest R, Milius H, Markusse R, Snel J. The sleep-wake experience list (De slaap-waak ervaring lijst). T Soc Gezondheidsz. 1989;10:343-7.

16. Meijman TF, de Vries-Griever AH, De Vries G, Kampman R. The evaluation of the Groningen sleep quality scale. Gron Heymans Bull HB 88-13-EX. Groningen: Groningen RUG; 1988.

17. Soldatos CR, Dikeos DG, Paparrigopoulos TJ. Athens Insomnia Scale: validation of an instrument based on ICD-10 criteria. J Psychosom Res. 2000;48:555-60.

18. Rosipal R, Lewandowski A, Dorffner $G$. In search of objective components for sleep quality indexing in normal sleep. Biol Psychol. 2013;94:210-20.

19. Westerlund A, Lagerros YT, Kecklund G, Axelsson J, Åkerstedt T. Relationships between questionnaire ratings of sleep quality and polysomnography in healthy adults. Behav Sleep Med. 2016;14:185-99.

20. Keklund G, Åkerstedt T. Objective components of individual differences in subjective sleep quality. J Sleep Res. 1997;6:217-20.

21. Argyropoulos SV, Hicks JA, Nash JR, Bell CJ, Rich AS, Nutt DJ, et al. Correlation of subjective and objective sleep measurements at different stages of the treatment of depression. Psychiatry Res. 2003;120:179-90.

22. Moustakas C. Phenomenological research methods. Thousand Oaks: SAGE Publications; 1994.

23. Hsieh H-F, Shannon SE. Three approaches to qualitative content analysis. Qual Health Res. 2005:15:1277-88.

24. Åkerstedt T, Orsini N, Petersen H, Axelsson J, Lekander M, Kecklund G. Predicting sleep quality from stress and prior sleep—a study of day-to-day covariation across six weeks. Sleep Med. 2012;13:674-9.

25. Pawlyk AC, Morrison AR, Ross RJ, Brennan FX. Stress-induced changes in sleep in rodents: models and mechanisms. Neurosci Biobehav Rev. 2008;32:99-117.

26. Eliasson AH, Kashani M, Mayhew M, Ude A, Hoffman J, Vernalis M. Reducing perceived stress improves sleep quality: a longitudinal outcomes study. Chest. 2010;138:913A-913A.

27. Åkerstedt T. Psychosocial stress and impaired sleep. Scand J Work Environ Health. 2006:32:493-501.

28. Sadeh A, Keinan G, Daon K. Effects of stress on sleep: the moderating role of coping style. Health Psychol. 2004;23:542.

29. O'Donnell D, Silva EJ, Münch M, Ronda JM, Wang W, Duffy JF. Comparison of subjective and objective assessments of sleep in healthy older subjects without sleep complaints. J Sleep Res. 2009;18:254-63.

30. Riedel BW, Lichstein KL. Objective sleep measures and subjective sleep satisfaction: how do older adults with insomnia define a good night's sleep? Psychol Aging. 1998;13:159-63.

31. Åkerstedt T, Hume K, Minors D, Waterhouse J. Good sleep_-its timing and physiological sleep characteristics. J Sleep Res. 1997;6:221-9. 